2. Karlinsky A, Kobak D. Tracking excess mortality across countries during the COVID-19 pandemic with the World Mortality Dataset. eLife. 2021;10:10. https:/ / doi.org/ 10.7554/eLife.69336

3. Barchuk A, Skougarevskiy D, Titaev K, Shirokov D, Raskina Y, Novkunkskaya A, et al. Seroprevalence of SARS-CoV-2 antibodies in Saint Petersburg, Russia: a population-based study. Sci Rep. 2021;11:12930. https:/ / doi.org/10.1038/s41598-021-92206-y

4. Zurochka A, Dobrinina M, Zurochka V, Hu D, Solovyev A, Ryabova L, et al. Seroprevalence of SARS-CoV-2 antibodies in symptomatic individuals is higher than in persons who are at increased risk exposure: the results of the single-center, prospective, cross-sectional study. Vaccines (Basel). 2021;9:627. https:/ / doi.org/10.3390/ vaccines 9060627

5. Cook S, Malyutina S, Kudryavtsev A, et al. Know Your Heart: rationale, design and conduct of a cross-sectional study of cardiovascular structure, function, and risk factors in 4,500 men and women aged 35-69 years from two Russian cities, 2015-18. Wellcome Open Research 2018;3:67. https:// doi.org/10.12688/wellcomeopenres.14619.3

6. Kuvshinova IN, Nekrasov BG, Livitskaya NI, Molodykh SV, Rukavishnikov M. Sensitivity and specificity of reagent kits of JSC "Vector-Best" for the detection of immunoglobulins of different classes to SARS-CoV-2 [in Russian]. Spravochnik Zaveduyushchego KDL. 2021;10:27-32.

7. Barchuk A, Shirokov D, Sergeeva M, Tursunzade R, Dudkina O, Tychkova V, et al. Evaluation of the performance of SARS-CoV-2 antibody assays for a longitudinal population-based study of COVID-19 spread in St. Petersburg, Russia. J Med Virol. 2021;93:5846-52. https:/ / doi.org/10.1002/jmv.27126

8. Sempos CT, Tian L. Adjusting coronavirus prevalence estimates for laboratory test kit error. Am J Epidemiol. 2021;190:109-15. https://doi.org/10.1093/aje/kwaa174

9. Government of Russia. The number of people vaccinated against coronavirus in Arkhangelsk [in Russian]. 2021 [cited 2021 Sep 20]. https://gogov.ru/covid-v-stats/arkhangelsk

10. European Centre for Disease Prevention and Control. Overview of the implementation of COVID-19 vaccination strategies and deployment plans in the EU/EEA, 14 June 2021. 2021 [cited 2021 Sep 20]. https:/ / www.ecdc.europa. $\mathrm{eu} / \mathrm{en} /$ publications-data/overview-implementation-covid19-vaccination-strategies-and-deployment-plans

Address for correspondence: David Leon, London School of Hygiene \& Tropical Medicine, Keppel St, London, WC1E 7HT, UK; email: david.leon@1shtm.ac.uk

\section{Ulceroglandular Infection and Bacteremia Caused by Francisella salimarina in Immunocompromised Patient, France}

\author{
Aurélie Hennebique, ${ }^{1}$ Yvan Caspar, ${ }^{1}$ Max Maurin, \\ Sandrine Boisset, Isabelle Pelloux, \\ Maria Pilar Gallego-Hernanz, Christophe Burucoa, \\ France Cazenave-Roblot, Chloé Plouzeau, \\ Blandine Rammaert
}

\begin{abstract}
Author affiliations: Université Grenoble Alpes, Grenoble
(A. Hennebique, Y. Caspar, M. Maurin, S. Boisset); CHU Grenoble Alpes, Grenoble, France (A. Hennebique, Y. Caspar, M. Maurin,

S. Boisset, I. Pelloux); CHU de Poitiers, Poitiers, France

(M.P. Gallego-Hernanz, C. Burucoa, F. Cazenave-Roblot,

C. Plouzeau, B. Rammaert); Université de Poitiers, Poitiers

(C. Burucoa, F. Cazenave-Roblot, B. Rammaert)
\end{abstract}

DOI: https://doi.org/10.3201/eid2802.211380

\begin{abstract}
Although Francisella tularensis is a well-known, highly virulent bacterium that causes tularemia in humans, other Francisella species have been associated with sporadic human infections. We describe a human cutaneous infection with bacteremia caused by F. salimarina, a Francisella species recently identified from seawater and fishes, in an immunocompromised patient in France.
\end{abstract}

A lthough the taxonomy of the genus Francisella includes a wide diversity of species, only $F$. tularensis subspecies tularensis and F. tularensis subsp. holarctica cause the potentially life-threatening disease tularemia (1). Several Francisella spp., including F. philomiragia, F. novicida, F. opportunistica, and F. hispaniensis, are occasional opportunistic human pathogens; the other Francisella spp. are not associated with human infections (1). We describe a human infection caused by F. salimarina, recently identified from aquatic environments and fishes.

In June 2017, a 76-year-old man received a diagnosis of acute myelomonocytic leukemia and was admitted to Poitiers University Hospital (Poitiers, France). The patient lived in a small town $30 \mathrm{~km}$ from the Atlantic Ocean, had not travelled abroad recently, and had no pets. The day after admission, first-line chemotherapy of subcutaneous azacitidine was started for 7 days. After 3 days of chemotherapy, piperacillin/tazobactam was introduced for 5 days because of febrile aplasia. The patient was then discharged with 
an antibiotic prophylaxis (sulfamethoxazole/trimethoprim at $800 \mathrm{mg} / 160 \mathrm{mg} 3 \times / \mathrm{wk}$ ). On July 26, the second azacitidine treatment was not administered because the patient again experienced febrile aplasia. Physical examination revealed skin lesions on 2 lefthand fingers that had appeared 3 weeks earlier. These lesions were erythematous and crusty but not purulent (Figure, panel A). They were associated with a left axillary lymphadenopathy. Antibiotic treatment with piperacillin/tazobactam and teicoplanin was started but was changed to imipenem/cilastatin and daptomycin after 5 days because of poor clinical response. Aerobic blood cultures performed at admission tested positive on July 31 and Gram stain showed a small gram-negative coccobacillus (Figure, panel B). Antibiotic treatment was changed to cefepime, administered for 3 days. No identification could be obtained by MALDI-TOF (matrix-assisted laser desorption/ ionization time-of-flight) mass spectrometry (Vitek MS; bioMérieux, https://www.biomerieux.com). The strain was identified as a Francisella spp. by $16 \mathrm{~s}$ rDNA amplification and sequencing. A cutaneous biopsy was performed because of persistent fever and worsening skin lesions in the patient; the same Francisella spp. strain was isolated. Doxycycline (100 mg $2 \times / d$ ) was administered for 8 days, followed by sulfamethoxazole/trimethoprim, which led to apyrexia.

The Francisella spp. strain (referred to as CHUGAF75) was sent to the French National Reference Centre for Francisella for further characterization. The strain was strictly aerobic and grew well on chocolate agar supplemented with IsoVitaleX (bioMérieux), blood agar, and tryptic soy agar, yielding gray mucoid colonies after $24 \mathrm{~h}$ of incubation at $35^{\circ} \mathrm{C}$ in $5 \% \mathrm{CO}_{2}$, but not on Drigalski agar (Figure, panels C, D). Biochemical testing revealed a positive oxidase, a weakly positive catalase, and a negative urease test. The strain was also halotolerant; it could grow in modified Mueller-Hinton broth with up to $8 \% \mathrm{NaCl}$. ISFtu2, Tul4, and type
B real-time PCR tests, which detected most Francisella spp., F. tularensis, and F. tularensis subsp. holarctica, were all negative for DNA extracted from this strain $(2,3)$. Species identification could not be obtained by using MALDI-TOF mass spectrometry, either with the routine database (MBT IVD Library DB-7171), the Biotox database (MBT SR Library; both from Bruker, https://www.bruker.com), or the French National Reference Centre for Francisella database containing F. tularensis, F. novicida, and F. philomiragia (4). Therefore, we performed whole-genome sequencing by using second and third next-generation sequencing platforms MiSeq (Illumina, https://www.illumina.com) and MinION (Oxford Nanopore Technologies, https:// nanoporetech.com). Hybrid assembly of the sequencing data using Unicycler software on the Galaxy web platform (https:/ / usegalaxy.org) enabled circularization of a 1,940,863 bp bacterial chromosome (Genbank accession no. CP076680). Whole-genome-based identification of the strain was assessed by using the Type Strain Genome Server (https://tygs.dsmz.de) (5). The CHUGA-F75 strain clustered in the same branch as the F. salimarina SYSU SYW-1, the F. marina E95-16, and the F. salina TX07-7308 strains (Appendix Figure, https:// wwwnc.cdc.gov/EID/article/28/2/21-1380-App1. pdf), probably representing the same species because of high genetic homology, although different species names have been published (6-8). Digital DNA-DNA hybridization $>70 \%$, average nucleotide identity $>95 \%$, and difference in percent guanine-cytosine content $<1$ percent between the CHUGA-F75 strain and the $3 \mathrm{~F}$. salimarina, F. marina, and F. salina strains confirmed the CHUGA-F75 isolate belonged to the same species. Because the only validly published species name according to the International Code of Nomenclature of prokaryotes is F. salimarina, we identified CHUGA-F75 as F. salimarina. Using the broth microdilution method in cation-adjusted Mueller-Hinton broth as recommended by the Clinical and Laboratory Standards
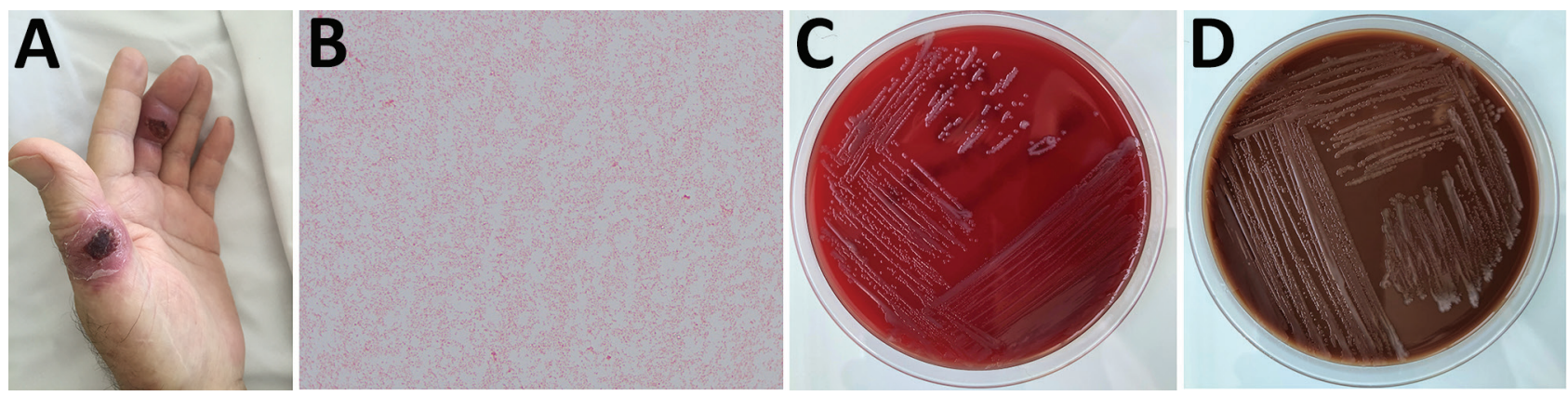

Figure. Skin ulcers and bacteremia caused by Francisella salimarina in an immunocompromised patient and isolated bacteria morphology, France. A) Skin lesion on 2 left-hand fingers. B) Small gram-negative coccobacillus isolated from blood and skin lesions (original magnification $\times 1,000$ ). C) Growth on blood agar after 2 days of incubation at $35^{\circ} \mathrm{C}$ in $5 \% \mathrm{CO}_{2}$. D) Growth on chocolate agar after 2 days of incubation at $35^{\circ} \mathrm{C}$ in $5 \% \mathrm{CO}_{2}$. 
Institute, we found that the CHUGA-F75 strain was sensitive to gentamicin $(\mathrm{MIC}=0.125 \mathrm{mg} / \mathrm{L})$, doxycycline $(\mathrm{MIC}=1 \mathrm{mg} / \mathrm{L})$, and ciprofloxacin $(\mathrm{MIC}=0.016 \mathrm{mg} / \mathrm{L})$ and resistant to sulfamethoxazole/trimethoprim $(\mathrm{MIC}=32 \mathrm{mg} / \mathrm{L})$.

F. marina was described as responsible for systemic disease in fishes (Lutjanus guttatus, the cultured spotted rose snapper) in Central America, whereas 4 F. salimarina strains have been isolated from costal seawater in Guangdong Province, China, and 1 strain of F. salina has been grown from brackish seawater and seaweed off the coast of Galveston, Texas, USA (6-8). To our knowledge, these Francisella spp. were not responsible for human infection so far. This report, like previous descriptions of human infections caused by emergent Francisella spp., highlights that environmental or fishrelated Francisella spp. could be responsible for opportunistic human infections resembling tularemia.

The Direction Générale de l'Armement of France funded this research (ANR-17-ASTR-0024).

\section{About the Author \\ Dr. Hennebique is a clinical microbiologist in the bacteriology laboratory of Grenoble University Hospital, Grenoble, France, which also hosts the French National Reference Center for Francisella tularensis. Her primary research interests are the tularemia agent, with an emphasis on its mechanisms of environmental survival in water, susceptibility to antibiotics, and virulence.}

\section{References}

1. Hennebique A, Boisset S, Maurin M. Tularemia as a waterborne disease: a review. Emerg Microbes Infect. 2019; 8:1027-42. https:// doi.org/10.1080/22221751.2019.1638734

2. Versage JL, Severin DDM, Chu MC, Petersen JM. Development of a multitarget real-time TaqMan PCR assay for enhanced detection of Francisella tularensis in complex specimens. J Clin Microbiol. 2003;41:5492-9. https:/ / doi.org/ 10.1128/JCM.41.12.5492-5499.2003

3. Kugeler KJ, Pappert R, Zhou Y, Petersen JM. Real-time PCR for Francisella tularensis types A and B. Emerg Infect Dis. 2006;12:1799-801. https:/ / doi.org/10.3201/ eid1211.060629

4. Regoui S, Hennebique A, Girard T, Boisset S, Caspar Y, Maurin M. Optimized MALDI TOF mass spectrometry identification of Francisella tularensis subsp. holarctica. Microorganisms. 2020;8:E1143. https://doi.org/10.3390/ microorganisms 8081143

5. Meier-Kolthoff JP, Göker M. TYGS is an automated high-throughput platform for state-of-the-art genomebased taxonomy. Nat Commun. 2019;10:2182. https:/ / doi.org/10.1038/s41467-019-10210-3

6. Challacombe JF, Petersen JM, Gallegos-Graves LV, Hodge D, Pillai S, Kuske CR. Whole-genome relationships among Francisella bacteria of diverse origins define new species and provide specific regions for detection. Appl Environ Microbiol. 2017;83:e02589-16.
7. Li L-H, Luo H-M, Feng J-H, Ming Y-Z, Zheng M-L, Deng G-Y, et al. Francisella salimarina sp. nov., isolated from coastal seawater. Int J Syst Evol Microbiol. 2020;70:3264-72. https://doi.org/10.1099/ijsem.0.004164

8. Soto E, Griffin MJ, Morales JA, Calvo EB, de Alexandre Sebastião F, Porras AL, et al. Francisella marina sp. nov., etiologic agent of systemic disease in cultured Spotted Rose Snapper (Lutjanus guttatus) in Central America. Appl Environ Microbiol. 2018;84:e00144-18. https://doi. org/10.1128/AEM.00144-18

Address for correspondence: Aurélie Hennebique, Service de Bactériologie-Hygiène Hospitalière, Institut de Biologie et de Pathologie, Centre Hospitalier Universitaire Grenoble Alpes, CS10217, 38043 Grenoble CEDEX 9, France; email: ahennebique@chu-grenoble.fr

\section{Surveillance of Rodent Pests for SARS-CoV-2 and Other Coronaviruses, Hong Kong}

Elliott F. Miot, ${ }^{1}$ Brian M. Worthington, ${ }^{1}$ Kar Hon Ng, ${ }^{1}$ Lucy de Guilhem de Lataillade, ${ }^{1}$ Mac P. Pierce, Yunshi Liao, Ronald Ko, Marcus H. Shum, William Y. Cheung, Edward C. Holmes, Kathy S. Leung, Huachen Zhu, Leo L. Poon, J.S. Malik Peiris, Yi Guan, Gabriel M. Leung, Joseph T. Wu, Tommy T. Lam

DOI: https://doi.org/10.3201/eid2802.211586

Author affiliations: University of Hong Kong State Key Laboratory of Emerging Infectious Diseases, Hong Kong, China (E.F. Miot, B.M. Worthington, K.H. Ng, L. de Guilhem de Lataillade, M.P. Pierce, Y. Liao, M.H. Shum, W.Y. Cheung, H. Zhu, Y. Guan, T.T. Lam); University of Hong Kong School of Public Health, Hong Kong (E.F. Miot, B.M. Worthington, K.H. Ng, L. de Guilhem de Lataillade, M.P. Pierce, Y. Liao, R. Ko, M.H. Shum, W.Y. Cheung, H. Zhu, L.L. Poon, M.J. Peiris, Y. Guan, G.M. Leung, J.T. Wu, T.T. Lam); University of Hong Kong HKU-Pasteur Research Pole, Hong Kong (E.F. Miot, L. de Guilhem de Lataillade, L.L. Poon, J.S.M. Peiris); Centre for Immunology \& Infection Limited, Hong Kong (E.F. Miot, L. de Guilhem de Lataillade, L.L. Poon,

${ }^{1}$ These coauthors contributed equally to this article. 